\title{
Cell signaling in root development Ben Scheres
}

\begin{abstract}
Cell signaling has recently been shown to be of major importance in cell specification during Arabidopsis root development. In the ground tissue, cues of unknown molecular nature convey positional information and two genes provide an interesting link between asymmetric cell division and the determination of cell fate. In the root epidermis, cell specification involves ethylene signaling and transcription factors of which at least two are also required for cell fate decisions in the shoot epidermis.
\end{abstract}

\section{Addresses \\ Department of Molecular Cell Biology, Utrecht University, Padualaan 8, $3584 \mathrm{CH}$ Utrecht, the Netherlands; e-mail: b.scheres@cc.ruu.nl}

Current Opinion in Genetics \& Development 1997, 7:501-506

http://biomednet.com/elecref/0959437X00700501

(C) Current Biology Ltd ISSN 0959-437X

$\begin{array}{ll}\text { Abbreviations } \\ \text { ACC } & 1 \text {-aminocyclopropane-1-carboxylate } \\ \text { AVG } & \text { aminoethoxyvinyl glycine } \\ \text { CTR1 } & \text { CONSTITUTIVE TRIPLE RESPONSE 1 } \\ \text { eto } & \text { ethylene overproducing } \\ \text { GL2 } & \text { GLABRA2 } \\ \text { SCR } & \text { SCARECROW } \\ \text { SHR } & \text { SHORTROOT } \\ \text { TTG } & \text { TRANSPARENT TESTA GLABRA }\end{array}$

\section{Introduction}

Anyone looking around in a flower shop may notice ornamental plants chimeric for pigmentation traits, their colour patterns a vivid display of cell lineage variability. Indeed, numerous studies of plant development indicate that cell lineage is, in most cases, variable and yet regular patterns of specialized cells arise [1]. As plant cells cannot undergo active movement, it is only common sense to suspect a key role for cell signaling in pattern formation and to presume that signaling takes place within the continuously developing regions of the plant - the meristems.

Within floral meristems, transcription factors are known to be involved in regional specification [2]; much less is known, however, about gene products that are required for signaling processes during pattern formation. Recently, a putative transmembrane kinase involved in cell differentiation and a candidate peptide growth factor have been discovered in plants, implying that intercellular signals similar to those employed in animals operate during plant development $[3,4]$. Nevertheless, surprisingly few studies on signaling pathways involved in plant cell specification exist that combine both genetic and experimental approaches. It has become clear recently that the Arabidopsis thaliana root allows such combined studies because of its regular cellular architecture, small size, and transparency. In this review, I focus on research carried out in the past two years on two examples of cell specification in the Arabidopsis root and sketch interpretations that may stimulate thought on the role of intercellular communication in plant cell specification.

\section{Cortex or endodermis: positional cues and asymmetric divisions}

The radial pattern of cell types in the Arabidopsis root reflects the organization of the three main tissues in the embryo axis (Figure 1) [5]. In the axial direction, cells are arranged in regular files that are extended at their basal ends by stereotyped cell divisions in the root meristem (Figure 1c). The distal-most root cap is produced by a separate set of meristem cells. Fate-mapping studies have revealed that the cell lineage of the root is largely invariant [6] - suggesting cell-autonomous development - but laser ablation studies demonstrate that positional signals are decisive for the determination of cell fate (see below). The specification of two ground-tissue-derived cell types - the cortex (cortical parenchyma) and the endodermis - serves well to illustrate this.

During embryogenesis, the ground tissue divides into two layers in the root, the innermost layer being the prospective endodermis (Figure 1c). Within the root meristem, the basal-most ground tissue cells usually remain undivided and they act as initial (stem) cells for cortex and endodermis. These initial cells continuously add new cells to the ground tissue. The daughters of the initial cells divide asymmetrically to form cortical and endodermal cells (after a few proliferative divisions) (Figures $1 \mathrm{c}$ and 2a). Laser ablation experiments have demonstrated that cells derived from a neighbouring tissue can switch fate in response to positional cues when they become located in the ground tissue layer ([7]; Figure $3 a-c)$. Blocking contacts between an initial cell and more mature daughter cells by laser ablation specifically inhibits the asymmetric division, giving rise to cortex and endodermis [7]. It was concluded that the initial cell requires signals to perform the asymmetric division and that these signals seem to originate from overlying more mature cells of the same tissue (Figure 3c). A recent study on plasmodesmal density and cell connectivity in the Arabidopsis root indicates that cells are most efficiently connected within their own tissue layer ( $\mathrm{T} Z \mathrm{Zhu}$, WJ Lucas, $T$ Rost, personal communication). In the epidermal layer, this connectivity persists until the cells are fully differentiated [8]. One could speculate that such a plasmodesmal network provides a structural framework for transport of tissue-specific specification signals. 
Figure 1

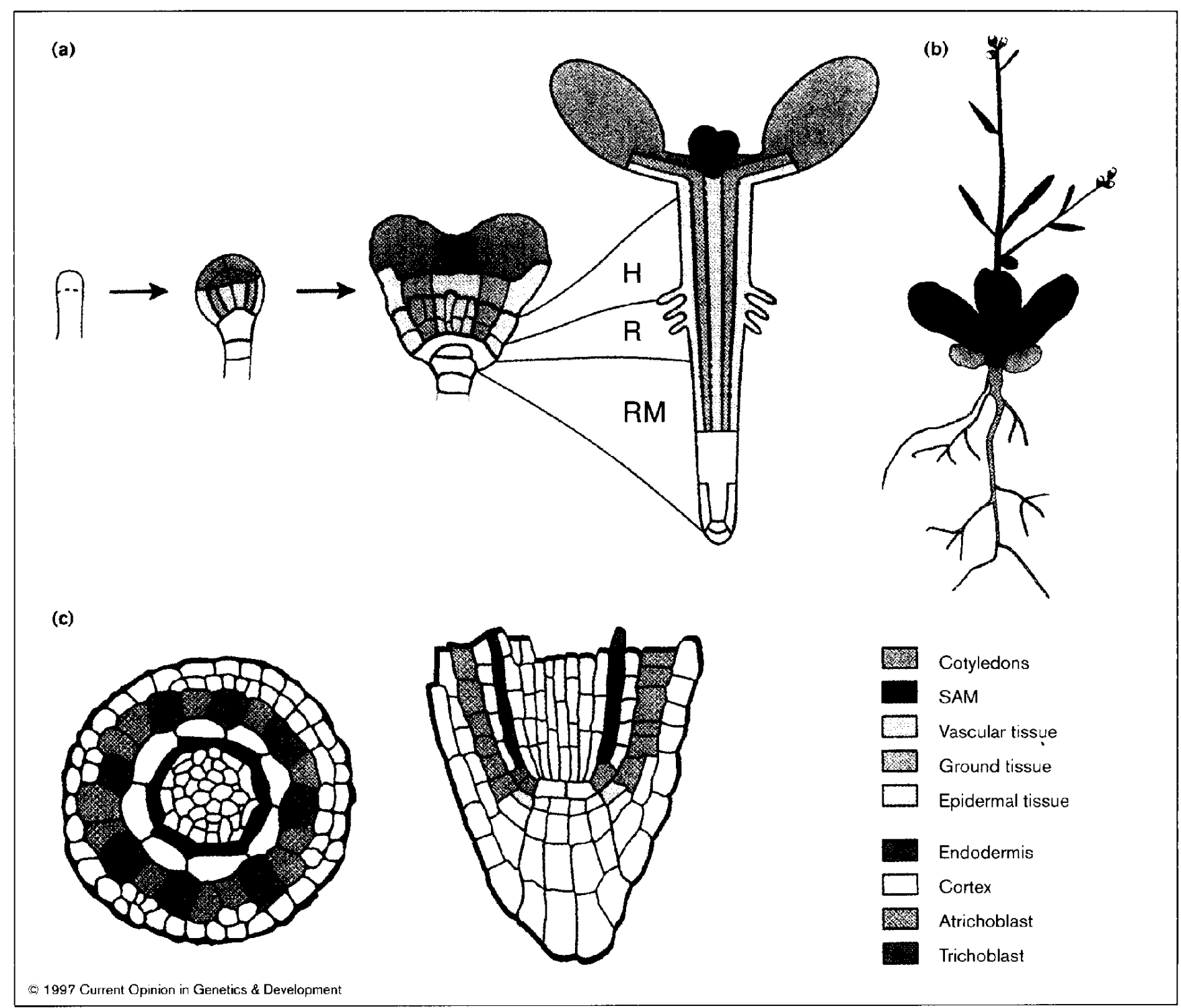

Ontogeny of meristems in Arabidopsis. (a) Embryogenesis results in a seedling containing the primary shoot apical meristem and derived leaves (SAM), the root meristem (RM) as well as three organ systems in the main axis: embryonic leaves (cotyledons), embryonic root (R) and hypocotyl $(\boldsymbol{H})$. The vascular, ground and epidermal tissues are shared by all organs, which are depicted only in the middle sections of the drawings. (b) The adult plant develops from the primary meristems and from newly formed secondary meristems. (c) Cross section and median longitudinal section through root meristem highlighting the epidermis-derived trichoblast and atrichoblast cells, and ground-tissue-derived cortex and endodermis.

Which genes are involved in the specification of cortex and endodermis? Plants homozygous for recessive mutations in the SHORTROOT (SHR) and SCARECROW (SCR) genes lack at least one ground tissue layer throughout the embryo axis $[9,10]$. In the root of shr mutants, the single remaining layer is lacking endodermal markers. In roots of sor mutants, a layer with mixed cortical/endodermal attributes remains $\left(\left[11^{\bullet} \cdot\right.\right.$; Figure 2$)$. The mixed cell type in $s c r$ mutants is unusual and interesting as mutations that interfere with asymmetric cell division in yeast and animals generally result in cells of one type [12]. The $\mathrm{shr}$ and ser phenotypes imply that the product of the $S H R$ gene is required to determine endodermal cell fate as well as for the asymmetric division and that the SCR gene is required specifically for the asymmetric division [1100]. Perhaps the $S C R$ gene is required exclusively for polarization of the cell and subsequent execution of an asymmetric division in a direction perpendicular to the proliferative divisions in the meristem (Figure 2b). In the brown alga Fucus, as well as in Caenorhabditis elegans, Drosophila, and mammals, polarized distribution of the cell fate determinants and alignment of cell division plane have been shown to be linked to the same underlying mechanism of polarity establishment ([13,14] and reference therein). The observation that $S H R$ is also required for asymmetric division may indicate that this 
Figure 2

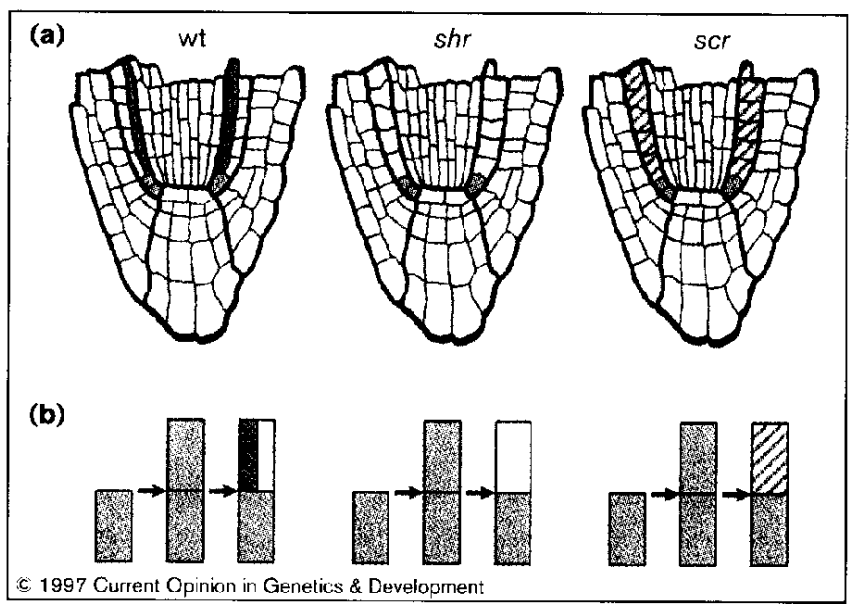

(a) shortroot (shr) and scarecrow (scr) mutants have altered cell fate and lack asymmetric cell division in the ground tissue layer. (b) Schematized division patterns and fate of cortex/endodermis initial cells in wild-type and mutant meristems.

gene is an upstream regulator of $S C R$. The $S C R$ gene has been cloned recently; it encodes several structural motifs, suggesting that the product is a transcription factor, and is expressed in the initial cells and throughout the endodermis in the meristem [11**].

Clarification is needed of how SCR function as a transcriptional regulator is related to cell division and the functional significance of persistent $S C R$ expression in the endodermis. Targeted expression of the $S C R$ gene in a sor mutant background should reveal whether endodermal expression of $S C R$ is of relevance for the asymmetric division of the initial cell. If so, the gene may regulate synthesis of the signal inferred from the laser ablation experiments mentioned above that triggers asymmetric division non-cell-autonomously. Taking this line of thought one step further by considering the observation that transcription factors can move through plasmodesmata ([15]; Jackson and Hake, this issuc, pp 495-500) a more tantalizing possibility is that the $S C R$ gene encodes the signal. Regardless of the eventual outcome, analysis of the relationship between the demonstrated signals and the $S C R$ and $S H R$ genes seems a promising route towards a better understanding of signaling processes in plant cell specification.

\section{Hairs or no hairs}

Although signals involved in specifying the cortex/ endodermis have not yet been characterized, cell specification within the epidermal layer is known to involve the phytohormone ethylene. This molecule acts as a signal in a variety of processes and corresponding receptors and signal transducers have been identified [16]. The epidermal cell layer of the Arabidopsis root comprises hair-bearing (trichoblast) and hairless (atrichoblast) cells in files along the main axis. Hair cell files form at predictable positions over the anticlinal walls of underlying cortex cells [5] (Figures 1c and 4). The consistency of this position-dependent distribution has enabled the analysis of trichoblast patterning.

A number of studies demonstrate collectively that ethylene positively regulates trichoblast development. First, ectopic root hairs are formed upon addition of the ethylene precursor 1-aminocyclopropane-1-carboxylate (ACC) in ethylene overproducing (eto) mutants and in plants homozygous for mutant alleles of the CONSTITUTIVE TRIPLE RESPONSE1 (CTR1) gene, which encodes a $R A F$ homologue negatively regulating ethylene signal

Figure 3
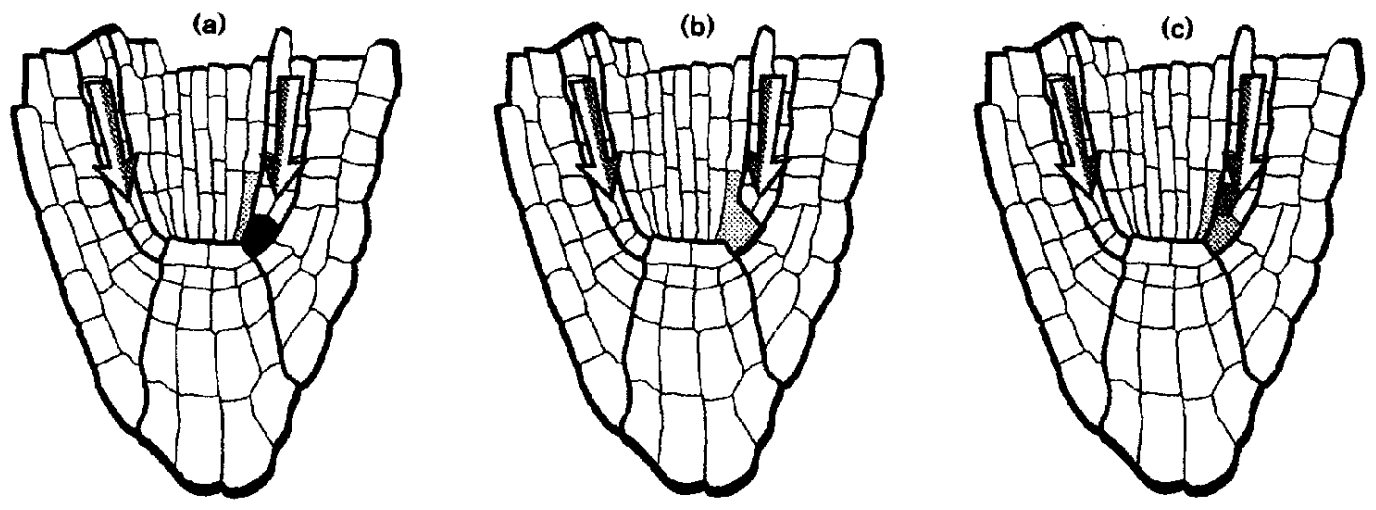

c) 1997 Current Opinion in Genetics \& Development

Positional cues in the Arabidopsis root. (a-c) Schematic representation of a laser ablation experiment. (a) Ground tissue initial ablation (black). (b) Invasion of cells from neighbouring tissue (red). (c) Daughters of invaded cells switch fate and act as ground tissue initials. The arrows indicate the proposed direction of positional cues. 


\section{Figure 4}

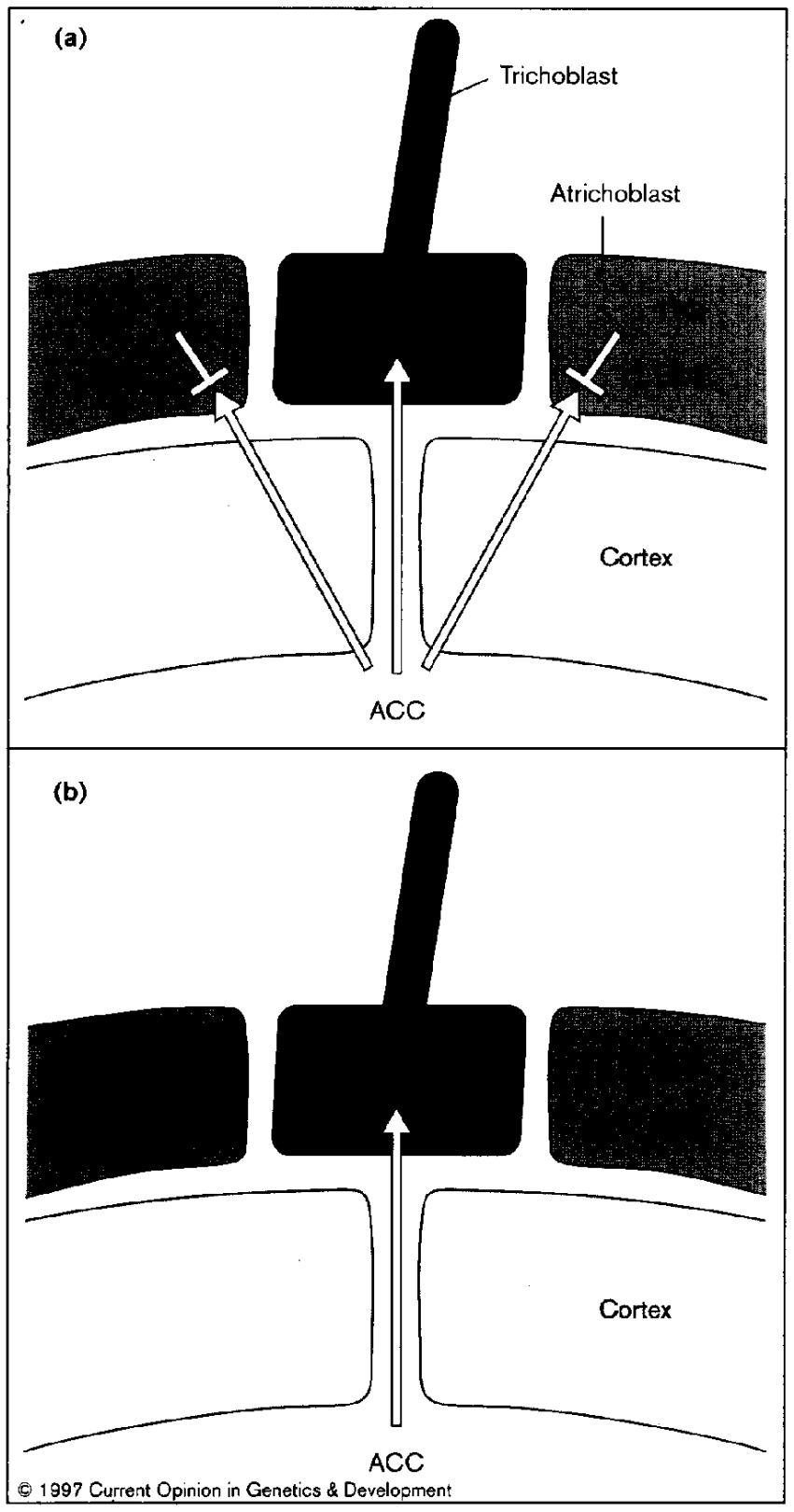

Models for the roles of negative (GL2) and positive (ethylene) inputs on trichoblast patterning. (a) Ethylene precursor (ACC) moves freely (arrows): ethylene activity is patterned by $T \mathrm{TG}$ and GL2 activity. (b) The ethylene precursor moves more readily through anticlinal clefts: ethylene pathway conveys independent patterning information.

transduction ([17,18]; XF Cao, L Dolan, personal communication). Second, a decrease in the number of hair cells is observed upon blocking either the synthesis or perception of ethylene with aminoethoxyvinyl glycine (AVG) and $\mathrm{Ag}^{+}$, respectively ([19]; XF Cao, L Dolan, personal communication).

Mutants lacking leaf hair cells have recently provided a convenient shortcut to additional genes involved in trichoblast patterning. Plants homozygous for recessive mutations in the TRANSPARENT TESTA GLABRA (TTG) and GLABRA2 (GL2) genes were found to possess ectopic root hairs on all epidermal cell filcs $\left[20,21^{\bullet}\right]$. The $T T G$ and $G L 2$ genes are thus required for negative regulation of trichoblast development in the non-hair-cell files. Surprisingly, the negative role of these genes in root hair cell specification contrasts with their positive role in leaf hair cell development.

The maize $R$ gene-encoding a myc transcription factor - can complement the $t g$ mutation, indicating that the $T T G$ gene either encodes or activates the Arabidopsis homologue of this transcription factor [22]. The GL2 gene encodes a homeodomain-containing a putative transcription factor [23]. GL2 mRNA levels are positively regulated by TTG [24]. Recently, the CAPRICE gene, encoding a protein with putative Myb DNA-binding motif but without an acidic activator domain, has been implied as an upstream GL2 repressor ( $\mathrm{T}$ Wada, Y Shimura, $\mathrm{K}$ Okada, personal communication). At least three interacting transcription factors are thus involved in atrichoblast specification.

To understand trichoblast patterning, it is important to locate the TTG/GL2 and ethylene activities both spatially and temporally. On the basis of in situ hybridization and reporter gene fusions, the GL2 gene is preferentially expressed in atrichoblast cell files well into the meristem region, consistent with a role in negative regulation of hair development in atrichoblasts $\left[21^{\bullet}, 25^{\bullet}\right]$. Treatment of ttg and gl2 mutants with the ethylene blocker AVG leads to the reduction of root hairs in all cell files, suggesting that the ethylene pathway is negatively regulated by TTG and GL2 in atrichoblast cells ([26*0]; Figure 4a). Timing experiments indicate that ethylene overproduction triggers ectopic root hair formation after the cessation of cell division, whereas ttg and $g / 2$ mutants display a phenotype in the meristematic region $\left(\left[26^{\circ}\right]\right.$; XF Cao, L Dolan, personal communication). Taken together, the data suggest that echylene appears to act at a late stage to promote root hair formation in cells where TTG/GL2 activity is either low or absent.

The possibility that ethylene also conveys positional information independently of TTG/GL2 activity deserves attention, as it is found that the remaining hairs in AVG-treated ttg/gl2 mutants form preferentially in the correct position [17]. This observation indicates that either endogenous ethylene production or the sensitivity of ethylene reception are patterned in the absence of $t \mathrm{tg} / \mathrm{gl} 2$ activity. An ethylene distribution pattern is conceivable as diffusion of the ethylene precursor ACC towards the epidermis may be facilitated through the anticlinal clefts over which trichoblasts normally reside ([27]; L Dolan, personal communication) (Figure 4b). If there are two prepatterns, an important issue is how they are put into register such that cells overlying cortical clefts respond to ethylene more readily and the remaining cells express 
GL2. One possibility, on the basis of differential epidermal sensitivity to ethylene, is that CAPRICE or similar gene products may be induced in trichoblast precursor cells by cues from the cortical clefts and subsequently set up both patterns by repressing $G L Z$ and simultaneously enhancing ethylene sensitivity.

\section{Conclusions}

Recent studies on cell specification in Arabidopsis roots are beginning to shed light on the role of intercellular communication in the determination of plant cell fate. In the ground tissue, hitherto uncharacterized signals appear to convey positional information and two genes have been identified that highlight an interesting and possibly plantspecific relationship between cell fate and asymmetric cell division. Trichoblast specification involves the relatively well characterized ethylene signaling pathway and a set of transcription factors also utilized in leaf hair formation. We may soon learn whether ethylene is a permissive signal or whether it also conveys positional information. We do not yet know enough of the two demonstrated signaling events to describe them in mechanistic detail but the experimental advantages of studying roots and the ongoing improvements of the Arabidopsis genetic model system may change this situation in the near future.

\section{Acknowledgements}

Research in the author's laboratory is supported by the Dutch Organization of Science (NWO), the Human Frontiers Science Program and the European Communicy, I thank Philip Benfey and Thomas Berleth for valuable discussions, my colleagues in the root group and Peter Weisbeek for critical reading of the manuscript, and Frouke Gerards-Kuyer for artwork.

\section{References and recommended reading}

Papers of particular interest, published within the annual period of review, have been highlighted as:

- of special interest

- of outstanding interest

1. Steeves TA, Sussex IM: Patterns in plant development. Cambidge: Cambridge University Press; 1989

2. Weigel D, Meyerowitz EM: The ABCs of floral homeotic genes. Cell 1994, 78:203-209.

3. Van de Sande K, Pawlowski K, Czaja I, Wieneke U, Schell J, Schmidt J. Walden R, Matvienko M, Wellink J: Modification of phytohormone response by a peptide encoded by ENOD4O of legumes and a nonlegume. Science 1996, 273:370-373.

4. Becraft PW, Stinard PS, MCCarty DR: CRINKLY4: a TNFR-like receptor kinase involved in maize epidermal differentiation. Science 1996, 273:1406-1409.

5. Dolan L, Janmaat K, Willemsen V, Linstead P, Poethig S, Roberts $\mathrm{K}$, Scheres B: Cellular organisation of the Arabidopsis root. Development 1993, 119:71-84.

6. Scheres B, Wolkenfelt $H$, Willemsen $V$, Terlouw $M$, Lawson $E$, Dean C. Weisbeek P. Embryonic origin of the Arabidopsis primary root and root meristem initials. Development 1994, 120:2475-2487.

7. Van den Berg C, Willemsen V, Hage W, Weisbeek P, Scheres B: Cell fate in the Arabidopsis root meristem determined by directional signalling. Nature 1995, 378:62-65.

8. Duckett CM, Oparka KJ, Prio DAM, Dolan L, Roberts K Dye-coupling in the root epidermis of Arabidopsis is progressively reduced during development. Development 1994 , 120:3247-3255.
9. Benfey $P$, Linstead $P$, Roberts $K$, Schiefelbein J, Hauser M-T, Aeschbacher R: Root development in Arabidopsis: four mutants with dramatically altered root morphogenesis. Development 1993, 119:57-70.

10. Scheres $B$, Di Laurenzio $L$, Willernsen $V$, Hauser $M-T$, Janmaat $K$, Weisbeek P, Benfey PN: Mutations affecting the radial organisation of the Arabidopsis root display specific defects throughout the embryonic axis. Development 1995, 121:53-62.

11. Di Laurenzio L, Wysocka-Diller J, Malamy JE, Pysh L, Helariutta -. $\quad Y$, Freshour G, Hahn MG, Feldmann KE, Benfey PN: The SCARECROW gene regulates an asymmetric cell division that is essential for generating the radial organization of the Arabidopsis root. Cell 1996, 86:423-433.

The authors demonstrate that the resulting single cell layer in the root of $\mathrm{scr}$ mutants has characteristics of two cell types. Molecular analysis of the SCR gene reveals that the deduced amino acid sequence contains several motifs suggestive of a function as transcription factor.

12. Hovitz HR, Herskowitz I: Mechanisms of asymmetric cell division: two Bs or not two Bs, that is the question. Cell 1992, 68:237-255.

13. Quatrano RS, Shaw SL: Role of the cell wall in the determination of cell polarity and the plane of cell division in Fucus embryos. Trend's Plant Sci 1997, 2:15-21.

14. White J, Strome $S$ : Cleavage plane specification in C. elegans: how to divide the spoils. Cell 1996, 84:195-198.

15. Mezitt LA, Lucas WJ: Plasmodesmal cell-to-cell transport of proteins and nucleic acids. Plant Mol Biol 1996, 32:251-273.

16. Ecker JR: The ethylene signal transduction pathway in plants. Science 1995, 268:667-675.

17. Tanimoto $M$, Roberts $K$, Dolan $L$ : Ethylene is a positive regulator of root hair development in Arabidopsis thaliana. Plant J 1995, 8:943-948.

18. Dolan L, Duckett CM, Grierson C, Linstead P, Schneider K, Lawson E, Dean C. Poethig S, Roberts K: Clonal relationships and cell patterning in the root epidermis of Arabidopsis. Development 1994, 120:2465-2474.

19. Masucci JD, Schiefelbein JW: The rhd6 mutation of Arabidopsis thaliana alters root-hair initiation through an auxinand ethylene-associated process. Plant Physiol 1994, 106:1335-1346.

20. Galway M, Masucci J, Lloyd A, Walbot V, Davis R, Schiefelbein J: The TTG gene is required to specify epidermal cell fate and cell patterning in the Arabidopsis root. Dev Biol 1994 166:740-754.

21. Masucci JD, Rerie WG, Foreman DR, Zhang $M$, Galway ME, Marks - MD, Schiefelbein J: The homeobox gene GLABRA2 is required for position-dependent cell differentiation in the root epidermis of Arabidopsis thaliana. Development 1996, 122:1253-1260.

In this paper, g/2 mutants are shown to display a partial conversion from atrichoblast to trichoblast cell. Analysis of GL2 promoter/GUS fusions and in situ hybridization demonstrates that the gene is preterentially expressed in atrichoblast cells. This is an important first step in defining the spatial requirements for the gene products involved in epidermal sub-specification.

22. Lloyd AM, Waibot V, Davis RW: Arabidopsis and Nicotiens anthocyanin production activated by maize regulators $\mathrm{R}$ and C1. Science 1992, 258:1773-1775.

23. Rerie WG, Feldmann KA, Marks MD: The GLABRA2 gene encodes a homeodomain protein required for normal trichome development in Arabidopsis. Genes Dev 1994, 8:1388-1399.

24. Di Cristina MD, Sessa G, Dolan L, Linstead P, Baima S, Ruberti I, Morelli G: The Arabidopsis Athb-10 (GLABRA2) is an HD-Zip protein required for regulation of root hair development Plant J 1996, 10:393-402.

25. Malamy JE, Benfey PN: Organisation and cell differentiation - in lateral roots of Arabidopsis thaliana. Development 1997, 124:33-44. 
Marker lines that express $\beta$-glucuronidase in a tissue- or cell-type-specific manner are used to analyze the post-embryonic formation of secondary root primordia. The paper demonstrates that a GL2 promoter/GUS fusion is expressed close to the epidermal initial cells within the meristem.

26. Masucci JD, Schiefelbein JW: Hormones act downstream of $\pi G$ and GL2 to promote root hair outgrowth during epidermis development in the Arabidopsis root. Plant Cell 1996, 5:1505-1517.
Epistasis studies and temporal separation of phenotypes indicate that phytohormone signalling acts downstream or independent of TTG and GL2 activity in trichoblast specification.

27. Rodrigues-Pousada RA, De Rycke R, Dedonder A, van Caeneghem W, Engler $G$, van Montagu $M_{1}$ van der Straeten $D$ : The Arabidopsis 1-aminocyclopropane-1-carboxylate synthase gene 1 is expressed during early development Plant Cell 1993, 5:897-911. 